\title{
Analysis of the Development of Abnormal Grains Structures During Beta Annealing of Ti-64 Wrought Products
}

\author{
+Nicholas E. Byres, +João Quinta da Fonseca, *Benjamin Dod, +Jack Donoghue, Alec Davis and +Phillip B. Prangnell
}

+MSS Tower, University of Manchester, Manchester, UK

*Airbus Operations SAS, Toulouse, France

\begin{abstract}
$\underline{\text { Abstract }}$
The B-annealing of Titanium-6Al-4V (Ti64) wrought aerospace components can lead to the development of abnormal grain structures (AGS) that jeopardise material performance. Therefore, an in-depth understanding into the origins of AGS will help in the design of processing routes that can avoid the conditions that lead to their development. This research demonstrates the application of novel concurrent in-situ heating and electron back scatter diffraction (EBSD) techniques to help elucidate possible mechanisms for the development of AGS. It was found that primary- $a\left(a_{p}\right)$ may play a key role, acting as a second phase particle, in pinning the $\beta$-phase grain boundaries during recrystallisation. The strengthening of a large area cube component texture macrozone, consisting of predominantly low angle grain boundaries, is also a prerequisite for the development of AGS.
\end{abstract}

\section{$\underline{\text { 1. Introduction }}$}

The microstructure of the alloy titanium 6 aluminium 4 vanadium (Ti64) can be tailored through thermomechanical processing, enabling its use in different aerospace applications. For example, $\beta$-annealing is used to produce a microstructure with high crack growth resistance which is desirable in many structural aerospace applications. In industry, the $\beta$-annealing of Ti64 components is carefully controlled to produce the required microstructure. Despite this, in some instances, a transformed- $\beta$ microstructure consisting of a coarse bimodal (and therefore abnormal) grain size distribution, referred to as an "abnormal grain structure" (AGS), appears in forgings with the abnormally large grains developing at the mid-section. This microstructure is unfit for purpose and therefore leads to rejected components. The development of AGSs is sometimes referred to as arising from abnormal grain growth [1] however, more recent research has demonstrated that the phenomena may be due to recrystallisation [2] and therefore "abnormal grain growth" is neither suitable nor physically descriptive of the correct mechanism.

In this paper we present the results of a set of novel in situ experiments designed to elucidate the conditions and mechanisms that lead to AGSs. This has involved the use of fast electron backscatter diffraction (EBSD) in a scanning electron microscope (SEM) equipped with a high temperature heating stage, to study in situ the microstructure and texture evolution in a representative $\beta$-annealed forging.

\section{$\underline{\text { 2. Materials and Methodology }}$}

2.1 Material studied

A Ti64 forged rectangular section, known to contain AGSs, from a starting $250 \mathrm{~mm}^{2}$ diameter billet was supplied by Airbus. The forging was sliced in half along the draw direction (DD) and one half subjected to an industry standard $\beta$-anneal, at $\mathrm{T}_{\beta}+30^{\circ} \mathrm{C}$ for 1 hour and air cooled, whilst the other half was retained in the as-forged condition. The specimen directions are defined as follows: $\mathrm{DD}=$ draw direction, $\mathrm{FD}=$ principle forging direction (maximum strain) and $\mathrm{TD}=$ transverse forging direction $(\mathrm{minimum}$ strain).

\subsection{Forged material - AGS - $\beta$-annealed microstructure}

An area of the $\beta$-annealed specimen that contained AGS was sectioned from the parent block into two specimens, one prepared for optical microscopy and the other prepared for EBSD microscopy by grinding to 4000 grit followed by 20 minutes of polishing, using a mixture of OPS/ $\mathrm{H}_{2} \mathrm{O}_{2}$ with a $4: 1$ ratio. Etching of the optical specimen was conducted using Kroll's reagent. The DD/FD plane of the abnormal region was mapped by EBSD, over a $25 \mathrm{x} 4 \mathrm{~mm}^{2}$ area using a voltage of $20 \mathrm{kV}$, step size of $10 u \mathrm{~m}$ and a working distance of $\sim 20 \mathrm{~mm}$. A sample from the corresponding "as-forged" section (non heat-treated) that married up to the location of the $\beta$-annealed section that exhibited AGS, was then selected for use in the in situ experiment. The EBSD data was analysed using the MTEX software package [3]. Reconstruction of the prior $\beta$-grain texture was achieved using software developed by Davies et al. [5], [6] at the University of Sheffield.

2.3 in situ EBSD mapping during $\beta$ annealing

A $2 \mathrm{~mm}^{3}$ cube of the as forged material was removed from the centre of the as-forged section. The DD/TD face was then prepared for EBSD analysis using the same grinding and polishing regime mentioned above. The specimen was then cemented onto the centre of a Gatan Murano heated specimen platform using carbon-based cement, and the cement cured for 2 hours at $25^{\circ} \mathrm{C}$, followed by a further 2 hours at $93{ }^{\circ} \mathrm{C}$ and a final 2 hours at $260{ }^{\circ} \mathrm{C}$ to ensure good electrical conductivity. A similar sized specimen of pure zirconium was also prepared and mounted to the heating chip alongside the Ti64 sample to act as an "oxygen-getter", in order to reduce the amount of latent oxygen in the microscope chamber that could absorb into the Ti64 sample during heating and increase the $\mathrm{T}_{\beta}$.

The in situ specimen was pre-heated to $300{ }^{\circ} \mathrm{C}$ to ensure efficient heating and contact of the thermocouple with the heating stage. After the pre-heat test, the system was left under vacuum at ambient temperature for approximately 16 hours to fully de-gas. The sample was then heated to progressively higher temperatures, within the $a+\beta$ phase regime, and isothermally held in order to carry out EBSD mapping. The EBSD scans were conducted at $20 \mathrm{kV}, 70^{\circ}$ tilt and at a working distance of $20 \mathrm{~mm}$. The scan size was approximately $1 \mathrm{~mm}^{2}$ with a step size of $1 \mathrm{um}$ for scans below $970{ }^{\circ} \mathrm{C}$ and $2 u \mathrm{~m}$ for scans above $970{ }^{\circ} \mathrm{C}$.

\section{Results}

3.1 Optical microscopy and EBSD mapping $\beta$-annealed forging - AGS

Optical microscopy of a $\beta$-annealed forged material that contains a typical AGS region is shown in figure figure 1 . The micrograph depicts the transformed- $\beta$ microstructure with homogeneous $a_{p}$ grains in the region towards the FD surfaces. However, at the mid-section of the sample, a low contrast region is seen where the unambiguous presence of prior $\beta$-grain boundaries become difficult to observe. Within this region, a large prior- $\beta$ island grain of approximately $6.5 \mathrm{~mm}$ in length can also be seen (red arrow). This type of microstructure, with a bimodal grainsize distribution, is typical of AGS. A black box indicates the size of the representative area of interest that was mapped by EBSD (figure 2). Initial EBSD analysis of the as-received, $\beta$-annealed forging given in figure 2, revealed the presence of very large abnormal prior $\beta$-grains of about $0.5 \mathrm{~cm}$ in size in the centre of the forging, that transformed on cooling to a typical, bimodal, $\beta$-transformed microstructure with thick $a_{p}$ colonies at their grain boundaries and fine $a$-lamella plates both within the prior ß-grains and in the surrounding matrix. 


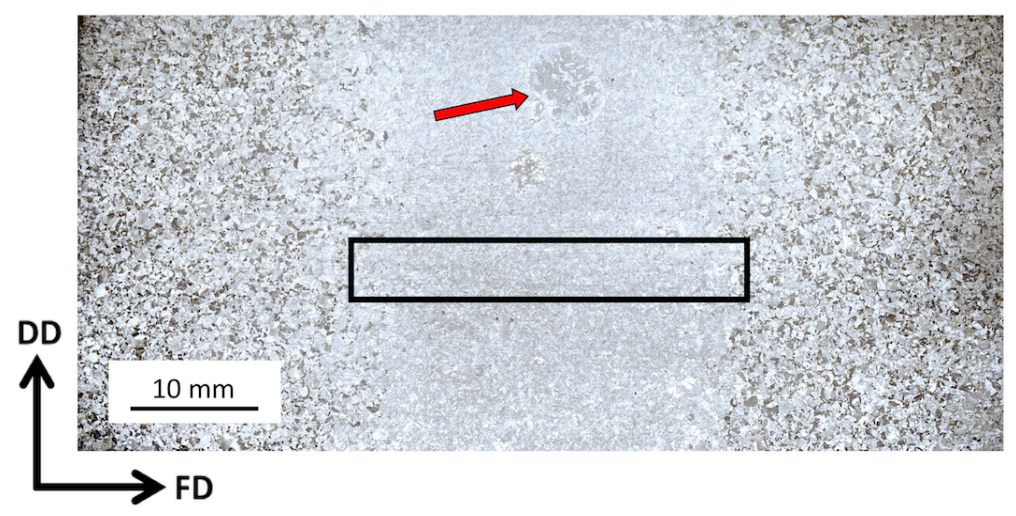

Figure 1: Optical micrograph of the B-annealed forged section with a ß-transformed microstructure. An abnormal grain (red arrow) and the representative area of interest (not the same region), that was mapped by EBSD (black box), shown in figure $2 \mathrm{~b}$ are indicated.

Reconstruction of the B-phase, from the orientations of the $a$-lamella colonies, revealed that the abnormal grains are surrounded by a large region of similar texture containing fine sub-grains with a $\{100\}<100>$ (cube) orientation. This region transitions from a small subgrain matrix to a region of larger, equiaxed grains with a much wider range of orientations, towards the surface of the forging. The region of equiaxed grains (seen toward the FD edges) extended for approximately $2 \mathrm{~cm}$ to each FD surface of the forging (not shown).
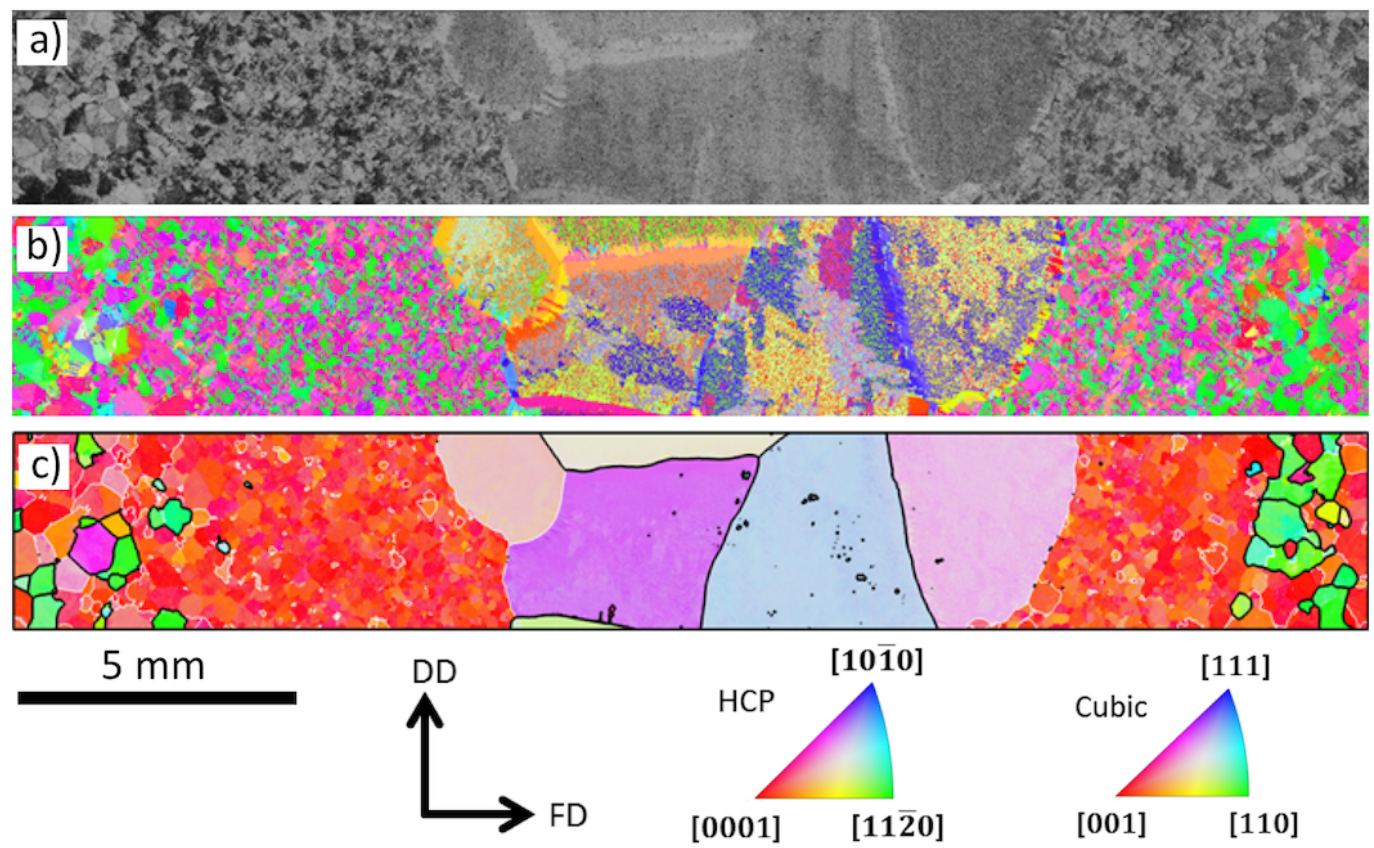

Figure 2: EBSD images of abnormal grains (centre) surrounded by small subgrain matrix along with larger prior B-grains with high angle grain boundaries at the FD surfaces. Maps were constructed using a) band contrast (a-phase) b) EBSD data (IPF $=$ FD) a-phase and c) reconstructed B-phase depicting high temperature prior B-grains.

\subsection{As forged microstructure}

A back-scatter SEM image of the centre of the as-forged starting material is shown in figure 3 depicting a bimodal microstructure with regions of $a_{p}$ and transformed- $\beta$, giving secondary- $a\left(a_{s}\right)$ with some retained $\beta$.

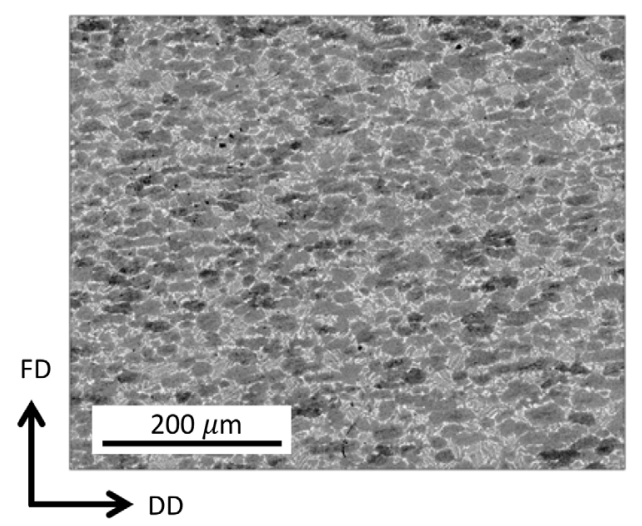

Figure 3: Back scattered SEM micrograph showing the starting microstructure of the as-received forged material used in this investigation, average $a_{p}$ grain size approximately 40 $u \mathrm{~m}$. 


\section{3 in situ $\beta$-annealing}

The region studied during the in situ heating experiment was obtained from the centre of the as-forged block and was selected to marry-up to the location in the $\beta$-annealed section that exhibited AGS. The starting textures of the $a$ and $\beta$ phases are shown in figure 4 (using EBSD maps) with corresponding pole figures obtained at $800{ }^{\circ} \mathrm{C}$. It can be seen that this region has a relatively strong $a$-texture with a $<11 \overline{2} 0>$ alignment in the $\mathrm{FD}(\max =3.6 \mathrm{~m} . \mathrm{r} . \mathrm{d})$ and $<0001>$ alignment approximately $45^{\circ}$ away from the $\mathrm{DD}$ and the TD ( $\max =5.4 \mathrm{~m} . \mathrm{r} . \mathrm{d})$. There is also evidence of texture banding (arrows), with regions showing $<0001>$ alignment with FD (red grains), aligned at approximately $25^{\circ}$ off FD, visible in the (0001) basal pole figure. The directly measured B-phase texture is also provided in figure 4 where the (001) pole figure demonstrates a very strong cube preferential alignment $(\max =13$ m.r.d). This texture component also dominated the central 'red' IPF colour region shown in figure 2.
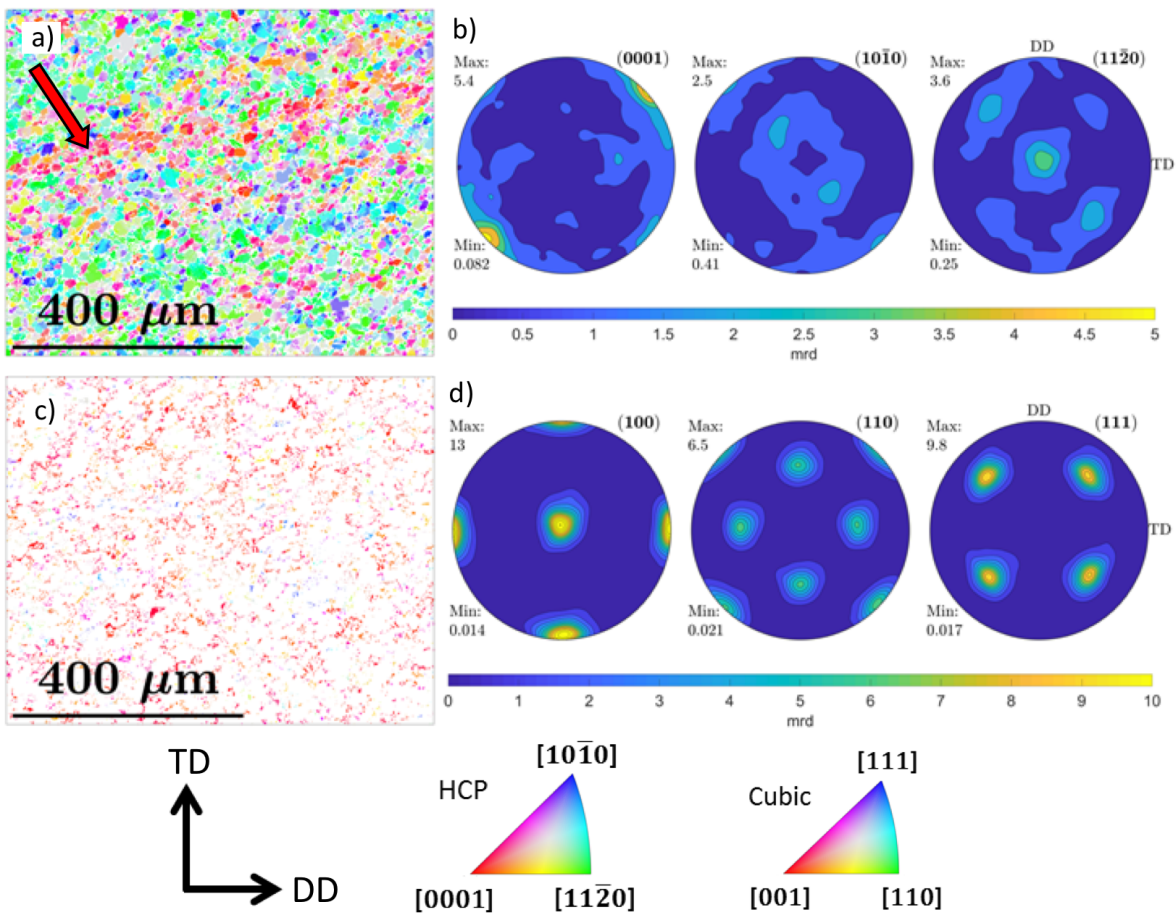

Figure 4: Texture representations of both the a-phase: a) IPF = FD with b) (0001), (1010) and (1120) pole figures and B-phase: $c)$ IPF $=$ FD with d) (100), (110) and (111) pole figures. (Minimum and maximum data given in multiples of random distribution (m.r.d))

The progression of the phase transformation tracked by in situ heating between $800{ }^{\circ} \mathrm{C}$ and $977{ }^{\circ} \mathrm{C}$ is shown in figure 5 . At $800{ }^{\circ} \mathrm{C}$ the $a$-phase had a volume fraction of about $90 \%$, existing as both $a_{p}$ and $a_{s}$. However, it was difficult to distinguish between $a_{p}$ and $a_{s}$ using only the EBSD map. Although the majority of the map area had the cube orientation, a few non-cube oriented $\beta$-grains could also be seen, some of which appeared to be associated to the $a$-phase texture band highlighted in figure 4 (red arrow).

At $940{ }^{\circ} \mathrm{C}$ (figure 5) the $a$-phase volume fraction had reduced to $16 \%$. Only large surviving $a$-grains (approximately $50 u$ m) could be seen in both the phase and $a$-IPF maps that correspond to $a_{p}$. Comparison of the phase map in figure $5 \mathrm{~b}$ and the IPF map in figure $5 \mathrm{~h}$ shows that the orientations of the newly transformed- 3 is the same as that of the B-grains that were present at $800^{\circ} \mathrm{C}$ (figure $5 \mathrm{~g}$ ). Therefore, whilst the dominant texture is still the cube texture, as before, there are also some highly misorientated grains present that have grown from the pre-existing misorientated $\beta$-phase nuclei that were seen at $800^{\circ} \mathrm{C}$

At $977^{\circ} \mathrm{C}$, the $a$-phase reduced to a volume fraction of only $2 \%$ (figure $5 \mathrm{c}$ ), which was somewhat unevenly distributed. The highly misorientated $\beta$-grains from within the $a$ phase texture band were, however, no longer present having been replaced by newly recrystallised grains that shared a similar orientation to that of the cube component.

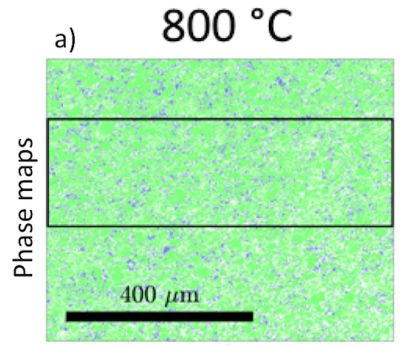

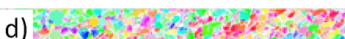

\section{$\alpha$}
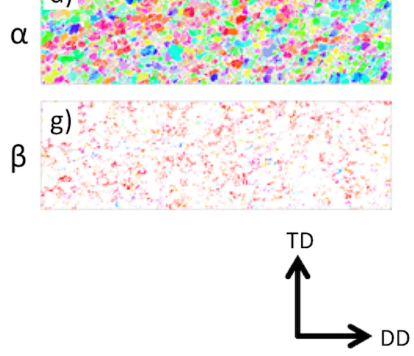

b) $\quad 940{ }^{\circ} \mathrm{C}$

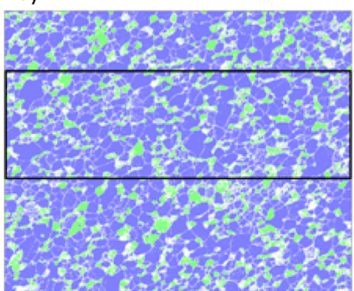

e)

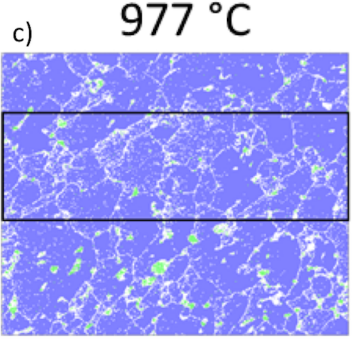

f)
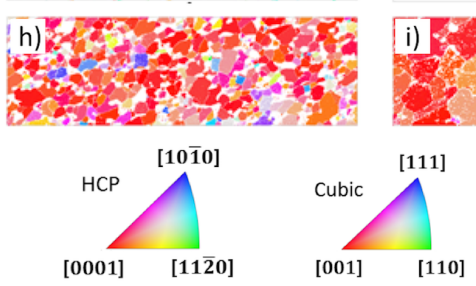
At $999^{\circ} \mathrm{C}$, the $a \rightarrow ß$ phase transformation was complete, as seen in figure 6 . The entire mapped surface now contained only $\beta$-phase subgrains whose orientations lay within $10^{\circ}$ of the ideal cube texture component. The (100) pole figure in figure $6 \mathrm{~b}$ also demonstrates an extremely sharp and strong cube texture (max $=45 \mathrm{~m}$. .d. .) whilst the misorientation histogram of figure $6 \mathrm{c}$ indicates that all the subgrain boundary misorientations were lower than $10^{\circ}$, with over $60 \%$ lower than $5^{\circ}$.
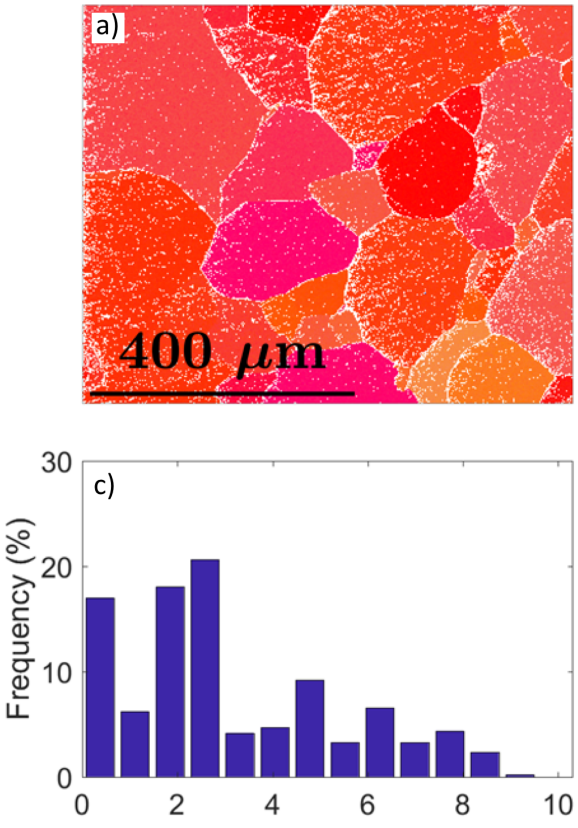

Misorientation angles in degree

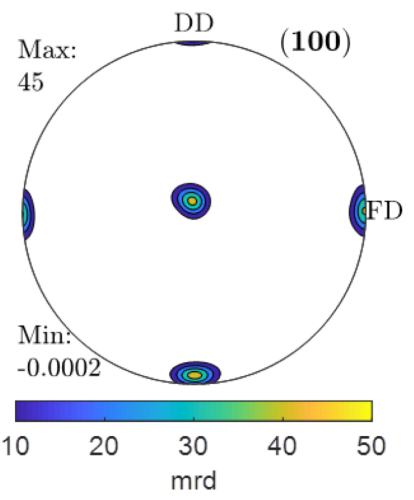

b)

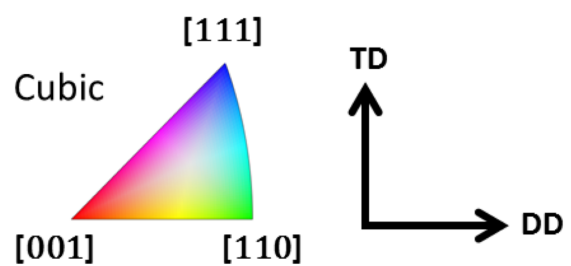

Figure 6: Final texture of the specimen once $100 \%$ B was achieved at $999^{\circ} \mathrm{C}$. IPF $=$ FD (a) depicts all red grains dominated by the cube texture, as seen in c) the pole figure of the EBSD data depicted in (a) demonstrating a very strong and sharp cube texture $(\max =45)$ and $b)$ the misorientation histogram demonstrating the low spread in grain boundary misorientations; note the maximum is below $10^{\circ}$ with $60 \%$ below $5^{\circ}$.

\section{Discussion}

Initial investigation into the AGSs in a $\beta$-annealed forged section by EBSD microscopy and reconstruction of the super-transus $\beta$-phase texture, unambiguously identified the presence of large abnormal grains with high angle grain boundary misorientations with respect to their surrounding matrix, that was composed of cube-aligned subgrains. They are therefore similar in nature to the coarse grains found in rolled plate [2] and probably grow in a similar manner, via recrystallisation. However, unlike in rolled plate, the number of grains that grow successfully was much lower in the forging, leading to only a few, but very large abnormal grains. This implies that conditions for this form of recrystallisation to occur happen only rarely in the forging studied here.

Annealing a specimen in situ, that exhibited a prior ß-phase consisting of a strong cube orientation, has demonstrated that the final texture that developed during transition through the $a+\beta$ phase field grows directly from the pre-existing $\beta$-phase orientations. This highlights the importance of controlling the $\beta$-phase texture during the prior deformation steps.

In the small area studied there were several highly misorientated non-cube oriented $\beta$-grains in the as-forged material that could have become new coarse grains after $\beta$ annealing. However, the experiment also showed that when the size of these misorientated grains is similar to that of the cube oriented subgrains of the surrounding matrix, the subgrains grow to consume the misorientated grains. This is consistent with a thermodynamic viewpoint, since high-angle grain boundaries have higher energy and therefore such grains will disappear on annealing, everything else being equal. The situation is further complicated here, however, since the remnant $a_{p}$ acts to pin grain boundaries.

The dissolution of $a$-phase occurs in a two-stage process. Initially, the finer lamellar $a_{s}$ transforms to $\beta$, re-growing from the retained $\beta$ orientations, leaving $a_{p}$ to act as second phase pinning particles in a classical 'Zener' sense. Figure $4 \mathrm{c}$ demonstrates this effect during the recrystallisation process, as regions pinned by less $a_{p}$ particles exhibit $\beta$-phase subgrains of larger size than those $\beta$-subgrains that are surrounded by $a_{p}$ at their boundaries. As a grain of high boundary mobility would need to reach a critical size with respect to its neighbours in order to enter a stage of discontinuous growth [7], as seen in AGSs in Ti-64, this may be a candidate mechanism that is capable of enabling the development of such microstructures. Further work is therefore needed to establish the effect of the heterogeneous dissolution kinetics of $a_{p}$ with respect to the $a$-phase texture bands that develop during $a+\beta$ phase deformation.

Texture banding in the $a$-phase (figure 5d) may also play a direct role in the development of misorientated $\beta$-grains that become embedded within the cube texture component. By comparing figures $5 \mathrm{~d}$ and e, there is evidence of a relationship in the location of $a$ and $\beta$-phase texture bands that suggests some form of mechanism is at play during concurrent deformation of the two phases that produces such highly misorientated grains within the subgrain matrix.

\section{Conclusions}

Large area EBSD mapping of a typical AGS microstructure and in situ heating with concurrent EBSD mapping of Ti64 forgings to simulate $\beta$-annealing has shown:

- Large abnormal ß-grains, of high boundary mobility, develop through uninhibited growth into a large macrozone matrix of low angle subgrains of a predominantly cube texture.

- Heterogeneous dissolution of $a_{p}$ may play an important role in determining the discontinuous recrystallisation behaviour of the $\beta$-phase during heating through the $a$ + B-phase window, which leads to AGSs.

- Regions of texture banding within the $a$-phase could provide the misorientated $\beta$-grains that act as nuclei for highly misorientated abnormal $\beta$-grain growth

- It is still unclear what exact conditions are needed for a highliy misorientated grain to undergo unstable growth in such a strongly textured region. We are planning to carry out computational simulations of this mechanism to study the competing effects of grain boundary pinning, misorientation and sub-grain size. 


\section{Acknowledgements}

The authors are appreciative of the EPSRC programme grants LightForm - EP/R001715/1 for supporting this research. Professor P.B. Prangnell is also grateful to the Royal Academy of Engineering UK and Airbus UK for financial support.

\section{$\underline{\text { References }}$}

[1] Gangshu Shen; David Furrer, Journal of Materials Processing Technology 98 (2000) 189-195

[2] Pilchak, A.L., Sargent, G.A. \& Semiatin, S.L. Metall and Mat Trans A, 49 (2018) 908.

[3] F. Bachmann et al., Solid State Phenomena, 160 (2010) 63-68,

[4] Semiatin, S.L., McClary, K.E., Rollett, A.D. et al. Metall and Mat Trans A, 43 (2012) 1649.

[5] P. S. Davies, “An Investigation of Microstructure and Texture Evolution in the Near- $\alpha$ Titanium Alloy Timetal 834,” University of Sheffield, 2009.

[6] P. S. Davies, B. P. Wynne, W. M. Rainforth, M. J. Thomas, and P. L. Threadgill, Metall. Mater. Trans. A Phys. Metall. Mater. Sci., 42 (2011) 2278-2289

[7] F. J. Humphreys, Acta Materialia, 45 (1997) 4231-4240 